\title{
Effects of Wall-Located Heat Barrier on Conjugate Conduction/Natural-Convection Heat Transfer and Fluid Flow in Enclosures
}

\author{
Erinç Hakyemez, Moghtada Mobedi \& Hakan F. Öztop
}

To cite this article: Erinç Hakyemez , Moghtada Mobedi \& Hakan F. Öztop (2008) Effects of Wall-Located Heat Barrier on Conjugate Conduction/Natural-Convection Heat Transfer and Fluid Flow in Enclosures, Numerical Heat Transfer, Part A: Applications, 54:2, 197-220, DOI: 10.1080/10407780802084447

To link to this article: http://dx.doi.org/10.1080/10407780802084447

曲 Published online: 19 May 2008.

Submit your article to this journal ๘

III Article views: 184

Q View related articles

4 Citing articles: 17 View citing articles 


\title{
EFFECTS OF WALL-LOCATED HEAT BARRIER ON CONJUGATE CONDUCTION/NATURAL-CONVECTION HEAT TRANSFER AND FLUID FLOW IN ENCLOSURES
}

\author{
Erinç Hakyemez ${ }^{1}$, Moghtada Mobedi ${ }^{1}$, and Hakan F. Öztop ${ }^{2}$ \\ ${ }^{1}$ Department of Mechanical Engineering, Izmir Institute of Technology, \\ Izmir, Turkey \\ ${ }^{2}$ Department of Mechanical Engineering, Firat University, Elazı̆̆, Turkey
}

The effects of a heat barrier, located in the ceiling wall of an enclosure, on conjugate conductionlnatural convection are investigated numerically. The vertical walls of the enclosure are differentially heated and the horizontal walls are adiabatic. Heatline technique is used to visualize heat transport. The variations of average Nusselt number, dimensionless heat transfer rate through the ceiling wall, and dimensionless overall heat transfer rate are studied. Calculations are performed for different Rayleigh numbers $\left(10^{3} \leq R a \leq 10^{6}\right)$, thermal conductivity ratios $(1 \leq K \leq 100)$, dimensionless locations of the heat barrier $\left(0<X_{h}<1\right)$, and two dimensionless ceiling wall thicknesses $(D=0.05$ and $D=0.20)$. For high thermal conductivity ratio $(K=100)$, the heat barrier considerably reduces the dimensionless overall heat transfer rate. The effect of the heat barrier on dimensionless heat transfer rate through the enclosure increases as the Rayleigh number decreases. For low Rayleigh number (i.e., $R a=10^{3}$ ), a location exists in the ceiling wall for which the dimensionless overall heat transfer rate is minimum.

\section{INTRODUCTION}

The influence of wall heat conduction on natural-convection heat transfer in enclosures has gained attention of researchers in recent years due to its importance in engineering applications such as cooling of electronic equipment, internal combustion engines, solar collectors, and heating and cooling of buildings. The aim of performed studies is to investigate the conductance effect of horizontal or/and vertical walls on natural-convection heat transfer through a cavity and, in some studies, conduction heat transfer rate through the walls.

The effect of wall conductance on natural convection in a square enclosure was investigated by Kim and Viskanta [1] for a cavity with surrounding thick frame, by Kaminski and Parakash [2] for an enclosure with a thick vertical wall, by Misra and Sarkar [3] for a square enclosure with a conducting vertical wall, by Yedder and Bilgen [4] for an enclosure bounded by a solid wall, by Liaqat and Baytas [5] for a square cavity containing a volumetric source and surrounded with a conducting thick frame, and by Varol et al. [6] for a thick-walled cavity at different wall

Received 11 October 2007; accepted 20 March 2008.

Address correspondence to Moghtada Mobedi, Department of Mechanical Engineering, Izmir Institute of Technology, 35430 Urla, Izmir, Turkey. E-mail: moghtadamobedi@iyte.edu.tr 


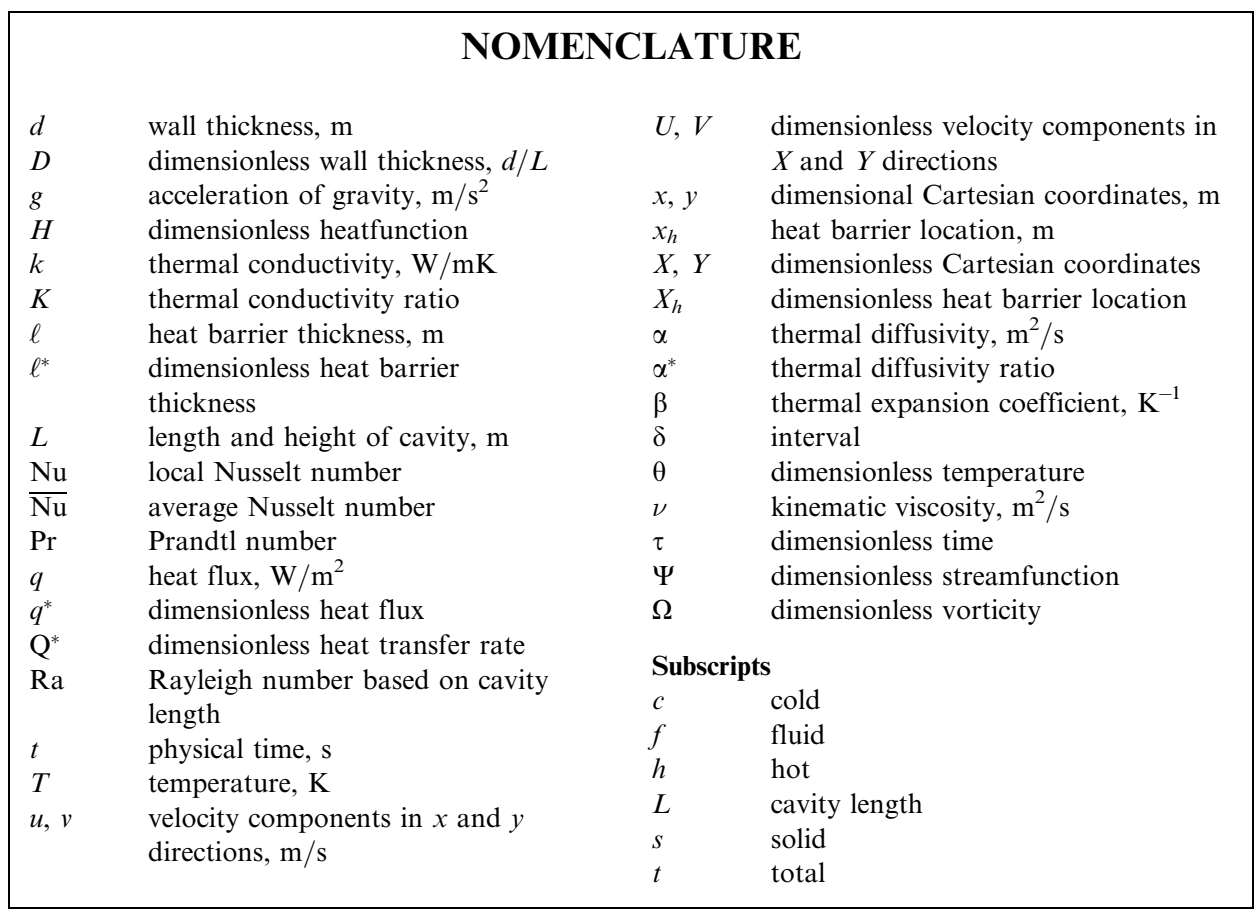

thicknesses. Kim and Viskanta [7], and Acharya and Tsang [8] studied conduction/ natural-convection heat transfer for a differently oriented square cavity. Furthermore, El-Shaarawi and Negm [9], and Morrone [10] investigated numerically the effect of a conduction wall on natural convection in an open-ended vertical concentric annulus and vertical parallel plates, respectively. The effects of both wall conduction and radiation were considered in the study of Kim and Viskanta [11] on heat transfer by conduction, natural convection, and radiation across a rectangular cellular structure. Rao [12] studied buoyancy-aided mixed convection with conduction and surface radiation from a vertical electronic board with a traversable discrete heat source.

The problem of thermal bridging is widely faced in industrial applications, particularly in building envelopes, metal casing panels, metal profiles, and window frames. A thermal bridge increases heat transfer between two walls and creates local temperature gradients on the walls, which may cause condensation problems on the wall surfaces. The transfer of heat through a thermal bridge has been investigated by Larbi [13] and by Ben Nakhi [14]. A temperature factor or thermal leakage coefficient was developed to measure the effect of a thermal bridge by Song et al. [15].

A heat barrier, known as a thermal breaker, can be located in the frame of rectangular enclosures to reduce heat leakage. The method is applied to metal profiles and panels of windows, doors, cold stores, and air conditioning equipment to thermally separate inside from outside surfaces and to provide uniform thermal resistance to prevent the possibility of condensation on the surfaces. For instance, the horizontal walls of a rectangular aluminum profile whose vertical walls are in 
contact with air at a different temperature causes thermal leakages, which can be prevented by using thermal barriers located in the horizontal walls. The number of studies on heat barriers, which are used for prevention of thermal bridges, is limited. Tosun et al. [16] performed a numerical study on the effect of a heat barrier on heat transfer through the profiles and panels of an air-handling unit casing. Höglund and Burstrand [17] performed an experimental study on slotted steel studs to reduce thermal bridging in insulated walls.

The heatline visualization technique is a useful tool in the study of heat barrier problems, since it changes the heat transport path. The technique was first proposed by Kimura and Bejan [18] to visualize heat transport in convective heat transfer. A detailed review study on applications of heatline was performed by Costa [19]. Mobedi [20] showed that the heatline visualization technique is a powerful method to show the interaction of heat transfer between solid and fluid interfaces.

The aim of this study is to investigate the effect of a heat barrier located in the ceiling wall of an enclosure on heat transfer through the ceiling wall and the fluid region of enclosure. The heat barrier considered is very thin and has infinite thermal resistance. It is located in the ceiling wall to prevent conduction heat transfer through the ceiling wall in the horizontal direction. Comparison of dimensionless heat transfer rate through the enclosures with and without heat barrier is performed to observe the effects of the heat barrier. The variations of dimensionless heat transfer rate through a heat barrier located in an enclosure with thermal conductivity ratio, heat barrier location, Rayleigh number, and dimensionless ceiling wall thickness are investigated. Streamlines, isotherms, and heatlines for the entire region are drawn to support discussions on the observed variations.

\section{THE PROBLEM CONSIDERED}

The models considered, which are enclosures with and without a heat barrier, are illustrated schematically in Figures $1 a$ and $1 b$, respectively. The cavity which contains air with $\operatorname{Pr}=0.71$, is square with side length $L$ and heat barrier location represented by $x_{h}$. The ceiling wall has finite thickness $d$, and the outer surfaces of floor and ceiling walls are insulated. The vertical walls of the cavity are maintained at different $T_{h}$ (left wall) and $T_{c}$ (right wall) constant temperatures such that $T_{h}>T_{c}$. The location of the heat barrier from the hot wall, $x_{h}$, is variable in this study. The heat barrier has small thickness $(\ell / L=0.001)$ and infinite thermal resistance. It has the same height as the ceiling wall. The heat transfer in the cavity occurs by laminar natural convection, and the radiation mode of heat transfer is omitted. The problem is solved for two different ceiling wall thicknesses, $d=L / 20$ and $d=L / 5$.

\section{GOVERNING EQUATIONS AND BOUNDARY CONDITIONS}

The governing equations for the problem are continuity, momentum, and energy equations for fluid inside the enclosure and the heat conduction equation for the ceiling wall. Gravity acts in the negative vertical direction, and the Boussinesq approximation is used. The pressure term in the momentum equation can be eliminated by using the vorticity-streamfunction approach. The steady results for the problem are obtained from the unsteady solution of the governing equations. By 


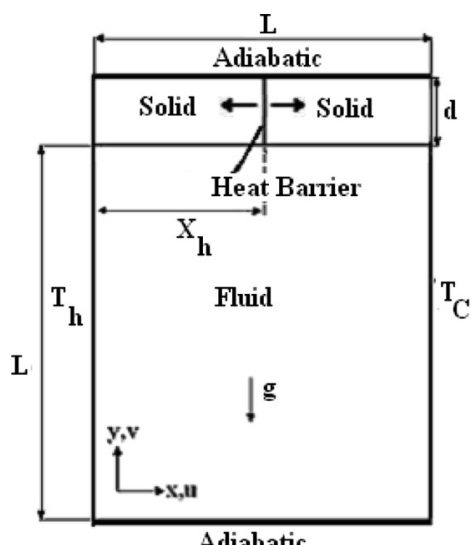

(a)

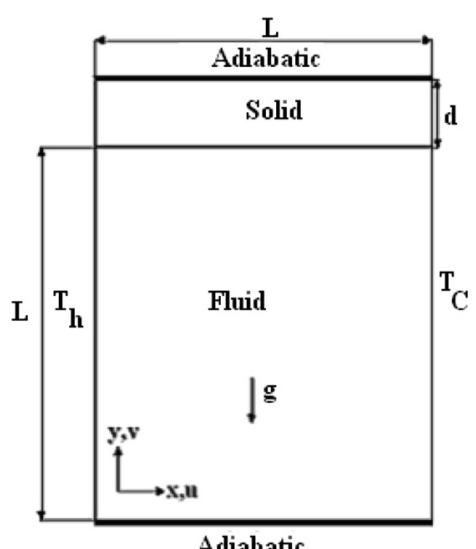

(b)

Figure 1. Schematic view of the cavities considered: $(a)$ ceiling wall with heat barrier; $(b)$ ceiling wall without heat barrier.

employing the dimensionless vorticity and streamfunction parameters, the dimensionless forms of the governing equations can be written as

$$
\begin{gathered}
\frac{\partial \Omega}{\partial \tau}+\frac{\partial U \Omega}{\partial X}+\frac{\partial V \Omega}{\partial Y}=\operatorname{Pr}\left(\frac{\partial^{2} \Omega}{\partial X^{2}}+\frac{\partial^{2} \Omega}{\partial Y^{2}}\right)+\text { Ra.Pr. } \frac{\partial \theta_{f}}{\partial X} \\
\frac{\partial^{2} \Psi}{\partial X^{2}}+\frac{\partial^{2} \Psi}{\partial Y^{2}}=-\Omega \\
\frac{\partial \theta_{f}}{\partial \tau}+\frac{\partial U \theta_{f}}{\partial X}+\frac{\partial V \theta_{f}}{\partial Y}=\frac{\partial^{2} \theta_{f}}{\partial X^{2}}+\frac{\partial^{2} \theta_{f}}{\partial Y^{2}}
\end{gathered}
$$

where $X, Y, U, V, \theta$, and $\tau$ are dimensionless parameters and are defined as

$$
\begin{aligned}
X & =\frac{x}{L} \quad Y=\frac{y}{L} \quad U=\frac{u L}{\alpha_{f}} \quad V=\frac{v L}{\alpha_{f}} \quad \theta_{f}=\frac{\left(T_{f}-T_{c}\right)}{\left(T_{h}-T_{c}\right)} \\
\tau & =\frac{\alpha_{f} t}{L^{2}}
\end{aligned}
$$

The dimensionless vorticity, streamfunction, and Rayleigh number are

$$
\begin{gathered}
\Omega=\frac{\partial V}{\partial X}-\frac{\partial U}{\partial Y} \\
U=\frac{\partial \Psi}{\partial Y} \quad V=-\frac{\partial \Psi}{\partial X} \\
\mathrm{Ra}=\frac{\mathrm{g} \beta\left(T_{h}-T_{C}\right) L^{3}}{\nu \alpha}
\end{gathered}
$$


Based on the defined dimensionless parameters, the dimensionless form of the heat conduction equation for the ceiling wall is

$$
\frac{\partial \theta_{S}}{\partial \tau}=\alpha^{*}\left(\frac{\partial^{2} \theta_{S}}{\partial X^{2}}+\frac{\partial^{2} \theta_{S}}{\partial Y^{2}}\right)
$$

where $\theta_{s}=\left(T_{s}-T_{c}\right) /\left(T_{h}-T_{c}\right)$ and $\alpha^{*}$ are the ceiling wall dimensionless temperature and thermal diffusivity ratio $\left(\alpha_{S} / \alpha_{f}\right)$. The boundary conditions for the domain shown in Figures $1 a$ and $1 b$ can be written as follows.

On the bottom wall,

$$
Y=0 \quad \Omega=-\frac{\partial U}{\partial Y} \quad \Psi=\frac{\partial \theta_{f}}{\partial Y}=0
$$

On the top wall,

$$
Y=1+D \quad \Omega=\Psi=\frac{\partial \theta_{S}}{\partial Y}=0
$$

On the left and right walls,

$$
\begin{array}{ll}
X=0, & X=1 \quad \Omega=\frac{\partial V}{\partial X} \\
\Psi=0 & \theta(0, Y, \tau)=1 \quad \theta(1, Y, \tau)=0
\end{array}
$$

On the ceiling solid-fluid interface,

$$
Y=1 \quad \Omega=-\frac{\partial U}{\partial Y} \quad \Psi=0 \quad \theta_{S}=\left.\theta_{f} \quad K \frac{\partial \theta_{S}}{\partial Y}\right|_{S}=\left.\frac{\partial \theta_{f}}{\partial Y}\right|_{f}
$$

For the right and left surfaces of the heat barrier with $\ell^{*}=\ell / L$ thickness,

$$
X=X_{h}+\frac{\ell^{*}}{2} \text { or } X=X_{h}-\frac{\ell^{*}}{2}, 1<Y<1+D, \quad \frac{\partial \theta_{S}}{\partial X}=0
$$

The thermal conductivity ratio and dimensionless wall thickness are shown by $K$ and $D$, respectively. The following initial values for the vorticity, streamfunction, and dimensionless temperature are used:

$$
\Omega=\Psi=\theta_{f}=\theta_{S}=0
$$

The dimensionless forms of the governing equations and boundary conditions reduce the number of independent dimensionless parameters to six, which are $\mathrm{Ra}, \mathrm{Pr}$, $K, \alpha^{*}, D$, and $X_{h}$. The thermal diffusivity ratio does not play a role in the steady-state results. The present study is performed for air with $\operatorname{Pr}=0.71$. Therefore, four dimensionless parameters, Rayleigh number, thermal conductivity ratio, dimensionless ceiling wall thickness, and dimensionless distance of the heat barrier from the hot wall, are taken into account. 
The following equation is solved to obtain the dimensionless heat function $[19,20]$ :

$$
\frac{\partial^{2} H}{\partial X^{2}}+\frac{\partial^{2} H}{\partial Y^{2}}=\frac{\partial U \theta}{\partial Y}-\frac{\partial V \theta}{\partial X}
$$

The dimensionless heat function in differential form is defined as

$$
-\frac{\partial H}{\partial X}=V \theta-\frac{\partial \theta}{\partial Y}, \quad \frac{\partial H}{\partial Y}=U \theta-\frac{\partial \theta}{\partial X}
$$

Equation (15), which is valid for both fluid and solid regions, can be solved numerically. The boundary conditions for Eq. (15) are obtained from the integration of Eq. (16) along the boundary considered. For example, the dimensionless heat function values at $X=0$ and $Y=1$ boundaries are determined as

$$
\begin{array}{ccc}
\text { At } X=0 \quad \text { and } \quad 0<Y \leq 1, & H(0, Y)=H(0,0)-\int_{0}^{Y} \frac{\partial \theta_{f}}{\partial X} d Y \\
\text { At } X=0 \text { and } 1<Y \leq 1+D, & H(0, Y)=H(0,1)-\int_{1}^{Y} K \frac{\partial \theta_{s}}{\partial X} d Y \\
\text { At } Y=1 \text { and } 0<X \leq 1, \quad H(X, 1)=H(0,1)+\int_{0}^{X} \frac{\partial \theta_{f}}{\partial Y} d X
\end{array}
$$

where, at the boundary $Y=0$, the values of heat function are considered zero, $H(X, 0)=0$.

\section{NUMERICAL SOLUTION PROCEDURE}

The governing equations [Eqs. (1)-(3)] are solved by starting from an initial state for the entire computational domain. The vorticity equation is solved for a time step to compute the vorticity field in the computational domain. Then, the streamfunction equation is solved and the velocity values are obtained from the streamfunction field. At the same time step and using the new values of velocity, the energy equation is solved and the temperature field is computed. The procedure is continued until steady state is reached [21]. The energy and vorticity equations are solved line by line by employing the alternating-direction implicit (ADI) method, whereas the streamfunction equation is solved point by point. The finite-difference forms of diffusion and convection terms are written based on three-point central differencing, which has second-order accuracy.

The value of Prandtl number for the flow region is assigned as 0.71 , while for the solid region it is changed to $\operatorname{Pr}=10^{20}$. This change of Prandtl number value makes the values of vorticity, streamfunction, and velocity in the horizontal wall automatically zero, and consequently the convection heat transfer equation is converted to the heat conduction equation of the ceiling wall. The temperature of the 
solid-fluid interface is obtained by employing backward and forward differences with first-order accuracy for determination of local heat flux. The vorticity values on the solid boundaries are calculated by using the relation developed by Wong and Baker [22]. The convergence criterion for the solution procedure is defined as

$$
\frac{\sum\left|\theta^{n+1}-\theta^{n}\right|}{\Delta \tau \sum \theta^{n}} \leq 10^{-4}
$$

where $\theta$ represents the dimensionless temperature in the entire computational domain. The local and average Nusselt numbers for a wall of the fluid region are calculated according to the gradient of dimensionless temperature in the normal direction of the considered wall. For instance, $\mathrm{Nu}$ and $\overline{\mathrm{Nu}}$ for the hot and cold vertical walls of the cavity $(X=0, X=1)$ are calculated by the following equations:

$$
\begin{gathered}
\mathrm{Nu}=\frac{q_{f} L}{k_{f}\left(T_{h}-T_{c}\right)}=-\left.\frac{\partial \theta_{f}}{\partial Y}\right|_{\text {wall }} \\
\overline{\mathrm{Nu}}=\int_{0}^{1} \mathrm{Nu} d Y
\end{gathered}
$$

The dimensionless heat transfer rate from a wall of the fluid region can be calculated as

$$
Q_{f}^{*}=\int_{0}^{1}-\left.\frac{\partial \theta_{f}}{\partial Y}\right|_{\text {wall }} d Y
$$

As is seen from Eqs. (22) and (23), the dimensionless heat transfer rate from a wall of the fluid region equals the average Nusselt number of that wall (i.e., $Q_{f}^{*}=\overline{\mathrm{Nu}}$ ), since the dimensionless height and width of the fluid region are unity. The dimensionless heat flux and heat transfer rate, $q_{s}^{*}$ and $Q_{s}^{*}$, from the vertical boundaries of the ceiling wall can be calculated by the following relations:

$$
\begin{gathered}
q_{s}^{*}=\frac{q_{s} L}{k_{s}\left(T_{h}-T_{c}\right)}=-\left.\frac{\partial \theta_{S}}{\partial X}\right|_{\text {wall }} \\
Q_{s}^{*}=\int_{1}^{1+D}-\left.\frac{\partial \theta_{S}}{\partial X}\right|_{\text {wall }} d Y
\end{gathered}
$$

In order to determine the dimensionless overall heat transfer rate from the vertical boundary of the enclosure, the definitions of $Q_{f}^{*}$ and $Q_{S}^{*}$ should be the same. The heat transfer rates should be nondimensionlized according to the same variables. Hence, the dimensionless heat transfer rate of the ceiling wall is multiplied by the thermal conductivity ratio. The dimensionless overall heat transfer rate to/from the entire area of the hot or cold vertical wall can be calculated by the following 
Table 1. $\overline{N u}$ and $Q_{t}^{*}$ of hot vertical wall for different number of grids for $\mathrm{Ra}=10^{6}$ and $K=100$.

\begin{tabular}{lcrr}
\hline Number of grids & & & \\
\cline { 1 - 2 } In cavity & In ceiling wall & & $\mathrm{Nu}$ \\
\hline $20 \times 20$ & $20 \times 6$ & 10.83 & $Q_{t}^{*}$ \\
$40 \times 52$ & $40 \times 12$ & 9.55 & 29.93 \\
$60 \times 85$ & $60 \times 25$ & 9.45 & 28.44 \\
$70 \times 110$ & $70 \times 40$ & 9.46 & 28.34 \\
$80 \times 130$ & $80 \times 50$ & 9.46 & 28.36 \\
\hline
\end{tabular}

equation:

$$
Q_{t}^{*}=Q_{s}^{*} K+Q_{f}^{*}
$$

Nonuniform mesh grid size was used for both the fluid and solid regions. The grid size was selected to be fine near the walls and heat barrier. They were expanded continuously toward the center of the enclosure. The number of nodes in the $X$ and $Y$ directions was $80 \times 130$, and $80 \times 50$ nodes were used in the ceiling wall. The smallest grid spacing, which was in the regions adjacent to the solid walls, was 0.001 . Table 1 shows the average Nusselt number of the hot vertical wall and the dimensionless overall heat transfer rate for different numbers of grids for $\mathrm{Ra}=10^{6}$ and $K=100$. As is seen, $80 \times 80$ grids for the fluid region and $80 \times 50$ grids for the solid region are sufficient to achieve accurate results for the problem.

\section{VALIDATION OF THE CODE}

In order to validate the method employed and to check the written computer code, results for the benchmark solution of de Vahl Davis [23] for nonconjugate natural convection in an air-filled square cavity were obtained and compared. Table 2 shows the comparison of the results of the two solutions. Another validation test was performed to check the accuracy of the conjugate solution. The comparison with the results of Kaminski and Prakash [2] is presented in Table 3. These tables show that there is good agreement between the results of the present code written for the conjugate conduction/convection heat transfer and reported studies in the literature. It should be mentioned that for all results obtained, the values of

Table 2. Comparison of the present numerical results with solution of de Vahl Davis [23]

\begin{tabular}{lcccc}
\hline & & \multicolumn{3}{c}{ Present study } \\
\cline { 3 - 5 } $\mathrm{Ra}$ & $\overline{{ }^{2}} \begin{array}{c}\text { de Vahl Davis } \\
|\psi|_{\max }\end{array}$ & $\overline{\mathrm{Nu}}$ & $|\psi|_{\max }$ & $\overline{\mathrm{Nu}}$ \\
\hline $10^{3}$ & - & 1.118 & 1.174 & 1.114 \\
$10^{4}$ & - & 2.243 & 5.109 & 2.240 \\
$10^{5}$ & 9.612 & 4.519 & 9.693 & 4.510 \\
$10^{6}$ & 16.750 & 8.800 & 16.916 & 8.803 \\
\hline
\end{tabular}


Table 3. Comparison between the results obtained and the solution of Kaminski and Prakash [2]

\begin{tabular}{|c|c|c|}
\hline $\mathrm{Ra}$ & $\frac{\text { Kaminski et al. }}{\overline{\mathrm{Nu}}}$ & $\begin{array}{l}\text { Present study } \\
\overline{\mathrm{Nu}}\end{array}$ \\
\hline \multicolumn{3}{|l|}{$7.1 \times 10^{2}$} \\
\hline$K=1$ & 0.87 & 0.866 \\
\hline$K=\infty$ & 1.06 & 1.062 \\
\hline \multicolumn{3}{|l|}{$7.1 \times 10^{4}$} \\
\hline$K=1$ & 2.08 & 2.074 \\
\hline$K=\infty$ & 4.08 & 4.034 \\
\hline \multicolumn{3}{|l|}{$7.1 \times 10^{5}$} \\
\hline$K=1$ & 2.87 & 2.850 \\
\hline$K=\infty$ & 7.99 & 7.911 \\
\hline
\end{tabular}

dimensionless overall heat transfer from the hot and cold boundaries were equal, which indicates the satisfaction of energy conservation for the entire domain.

\section{RESULTS AND DISCUSSION}

The results obtained are presented via dimensionless heat transfer rate from the ceiling wall boundaries, mean Nusselt numbers of the fluid region walls, and dimensionless overall heat transfer rate of the enclosure for the cases with and without heat barrier. The effects of heat barrier location, ceiling wall thickness, and Rayleigh number on $\overline{\mathrm{Nu}}, \mathrm{Q}_{s}^{*}$, and $Q_{t}^{*}$ for a heat barrier located in an enclosure are investigated and discussions are given in the-under-following subsections. The height and width of the fluid region are unity; therefore, $\overline{\mathrm{Nu}}$ represents the dimensionless heat transfer rate $\left(\mathrm{Q}_{\mathrm{f}}^{*}\right)$ to/from the fluid region at the same time.

\subsection{Effect of Heat Barrier}

The heat barrier can be placed at different locations on the ceiling; however, results of a middle-located heat barrier enclosure with $D=0.2$ ceiling thickness are considered in this section to describe the heat barrier effects. Figure 2 shows the effects of the heat barrier on flow fields, temperature distributions, and heat transport using the isotherms (on the left), streamlines (on the middle), and heatlines (on the right) of two enclosures without a heat barrier (Figure $2 a$ ) and with a heat barrier (Figure $2 b$ ) for $\mathrm{Ra}=10^{3}$ and $K=1$. The value written on the top of the heatline figures represents the dimensionless overall heat transfer rate. A single circulation cell is formed in clockwise rotation in the fluid region as shown from the streamlines. The isotherms and streamlines in the fluid region of both enclosures (with barrier and without barrier) are similar to each other. The existence of the thermal barrier does not considerably affect heat transfer rate through the fluid region of the enclosure. However, the direction of heat flow is changed around the heat barrier in the ceiling. Heat cannot be transferred directly from the hot to the cold vertical wall due to the existence of the heat barrier. It is transferred from the hot region of the ceiling to the fluid and then it passes to the cold region of the ceiling wall. Hence, a reduction in the heat transfer through the ceiling should be expected. 

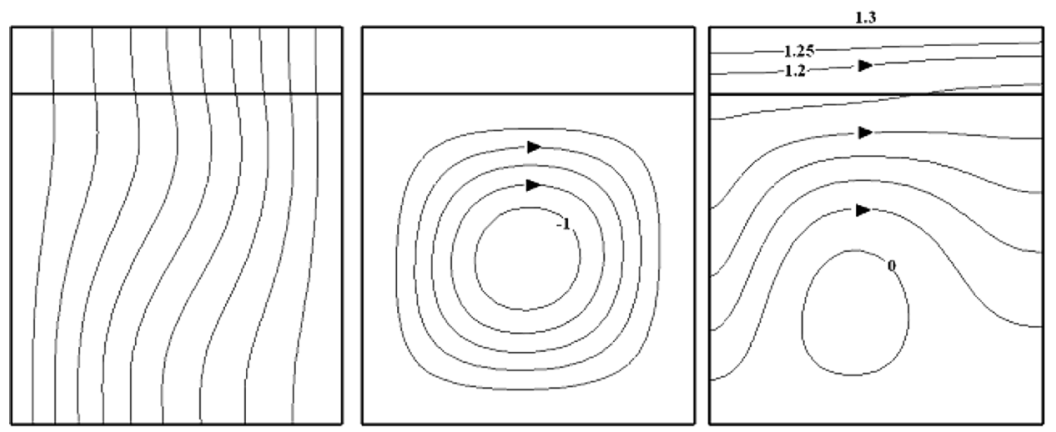

(a)
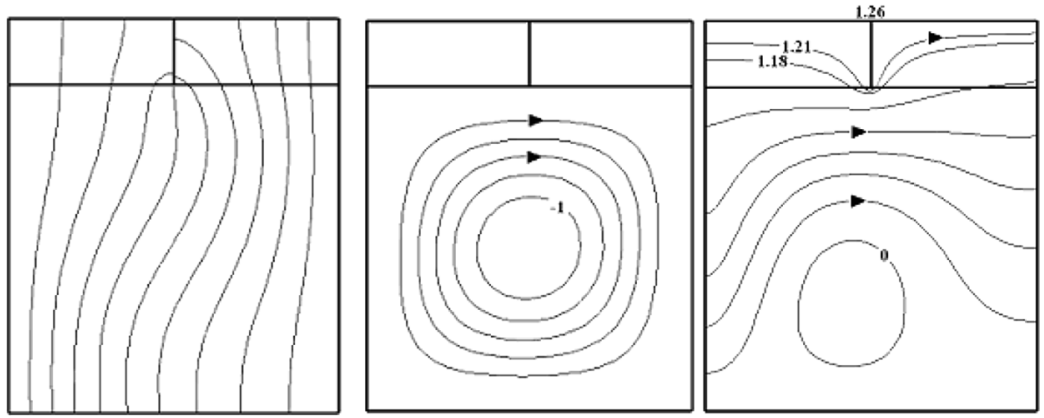

(b)

Figure 2. Isotherms (on the left), streamlines (on the middle), and heatlines (on the right) for $\mathrm{Ra}=10^{3}$ and $K=1$ : $(a)$ without heat barrier, where $\delta \theta=0.1, \delta \Psi=-0.2, \delta H=0.22$ (heatlines 1.2 and 1.25 were added); $(b)$ with middle-located heat barrier, where $\delta \theta=0.1, \delta \Psi=-0.2, \delta H=0.21$ (heatlines 1.18 and 1.21 were added).

Results are presented in Figure 3 for $\mathrm{Ra}=10^{3}$ and $K=100$ to see the effects of high conductivity ratio on flow and temperature fields of the enclosures with and without heat barrier. Similar to the case of Figure 2, the isotherms in the ceiling without heat barrier are parallel due to the high conductivity ratio, and they are nearly parallel in the fluid region. The great amount of heat is transferred directly from the hot to the cold vertical wall via conduction mode of heat transfer in the ceiling wall. The heat barrier prevents transfer of heat from the hot to the cold vertical wall of the ceiling. Two separate hot and cold regions with almost uniform temperature distributions form at the right and left sides of the heat barrier, due to the high thermal conductivity ratio. Hence, isotherms in the upper side of the fluid region are distributed from the edge of the heat barrier. The formation of separate hot and cold regions in the ceiling wall with heat barrier for high values of $K$ (i.e., $K=100$ ) can also be observed from Figure 4, in which the ceiling interface temperature distributions for $\mathrm{Ra}=10^{3}$ and different $K$ values are shown. A small gap at the heat barrier location can be seen in the interface temperature of $K=1$, since heat transport and fluid flow in most of the enclosure is not greatly influenced by the heat barrier. The gap between the temperatures of the left and right sides of the heat barrier increases with increasing $K$, and a sharp drop is 

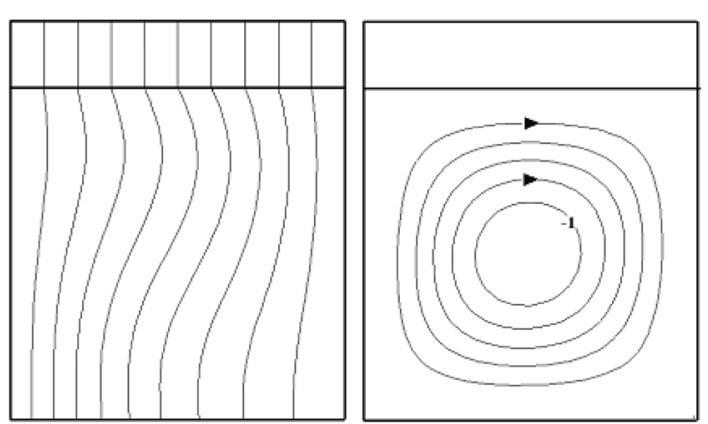

(a)
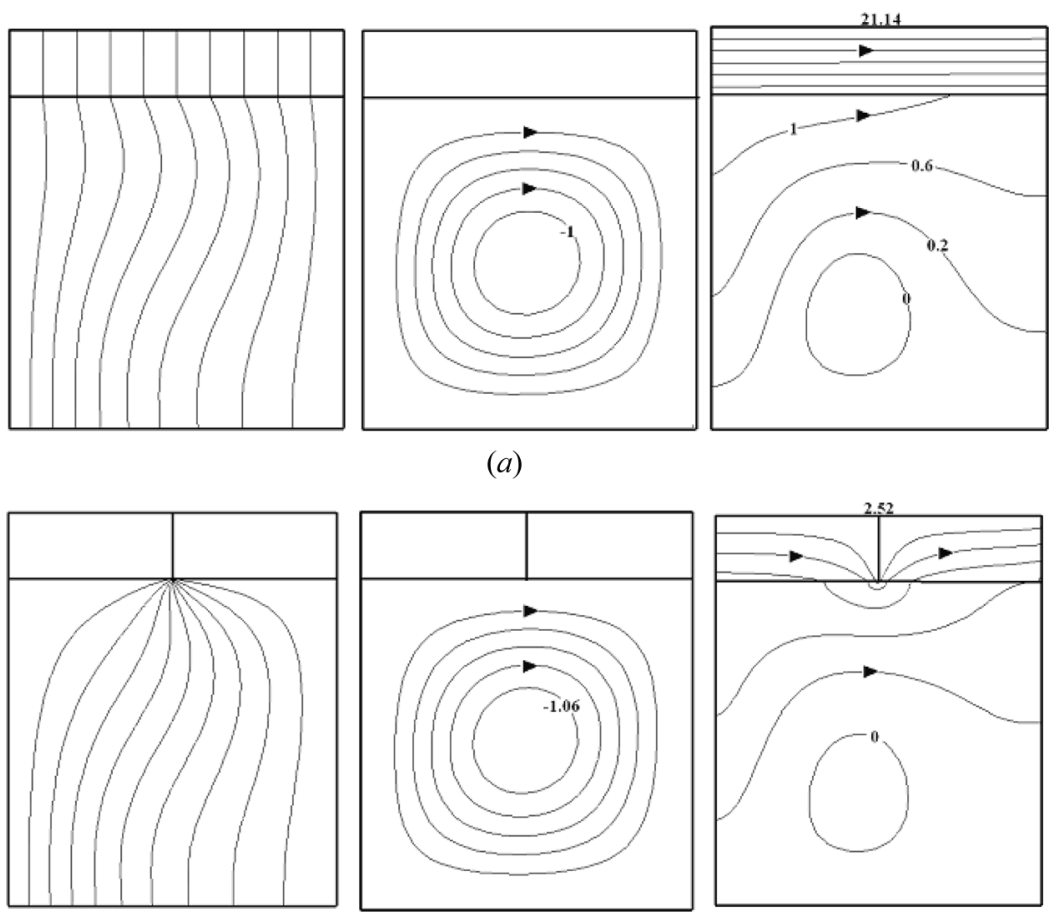

(b) 

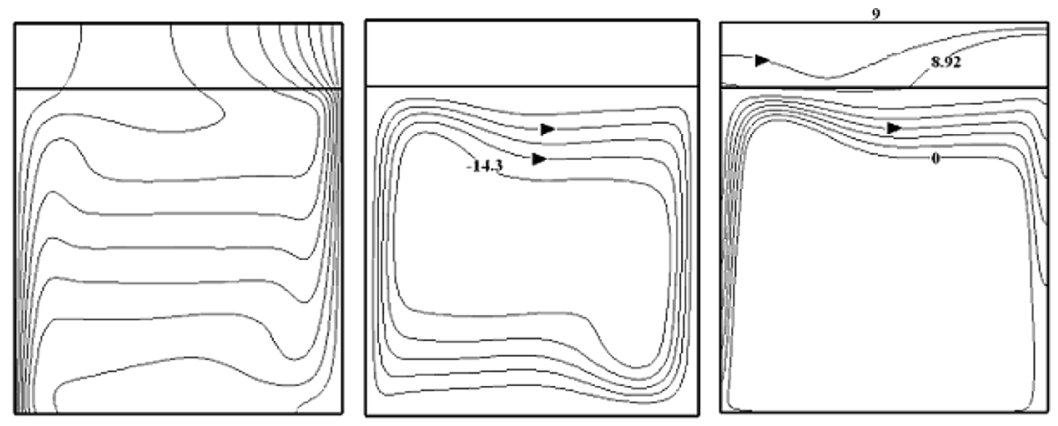

(a)
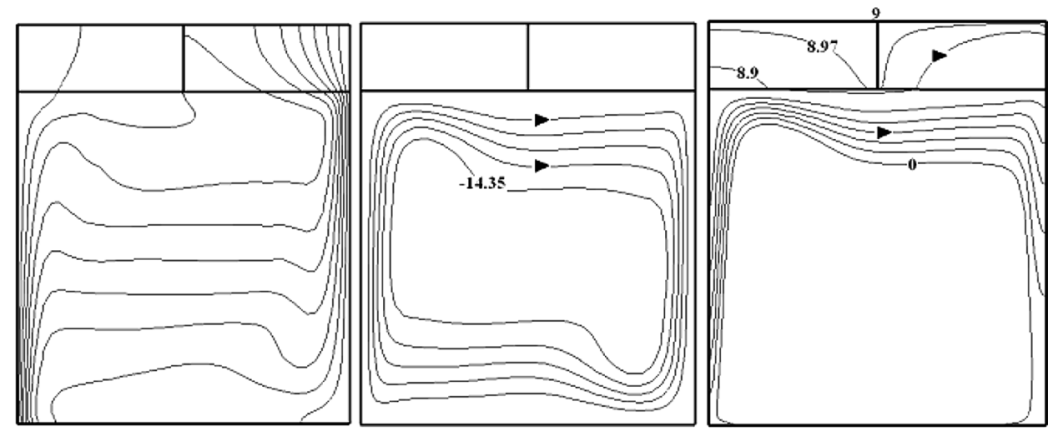

(b)

Figure 5. Isotherms (on the left), streamlines (on the middle), and heatlines (on the right) for $\mathrm{Ra}=10^{6}$ and $K=1:(a)$ without heat barrier, where $\delta \theta=0.1, \delta \Psi=-2.86, \delta H=1.5$ (8.92 and 8.98 were added); $(b)$ with middle-located heat barrier, where $\delta \theta=0.1, \delta \Psi=-2.87, \delta H=1.5$ (8.9 and 8.97 were added).

Figure 5 shows isotherms (on the left), streamlines (on the middle), and heatlines (on the right) for the enclosure with $\mathrm{Ra}=10^{6}$ and $K=1$ without (Figure $5 a$ ) and with (Figure $5 b$ ) a heat barrier. For both cases, the convection effect is dominant and most of the heat in the fluid region is transferred via convection. Since the conduction in the ceiling wall is weak, the existence of the heat barrier does not considerably change isotherms and streamlines in most of the fluid region. However, heat transfer through the ceiling is affected by the heat barrier, since the direction of heat flow is changed.

Effects of the highest conductivity ratio on isotherms, streamlines, and heatlines are given in Figure $6 a$ (without barrier) and Figure $6 b$ (with barrier) for $\mathrm{Ra}=10^{6}$. The conduction in the ceiling wall is strong and, similar to the case of Figure 3, the isotherms are joined at the edge of the heat barrier due to the formation of hot and cold regions. The heat barrier should have a significant effect on heat transfer through the ceiling wall, as seen from heatlines and isotherms.

The variations of average Nusselt number at the hot and cold vertical walls and the interface with thermal conductivity ratio are seen in Figures $7 a$ and $7 b$ for $\mathrm{Ra}=10^{3}$ and $\mathrm{Ra}=10^{6}$, respectively. For the cavity with $\mathrm{Ra}=10^{3}$, the heat barrier reduces the values of average Nusselt number at the hot and cold vertical walls of the fluid region. However, it enhances the heat transfer on the interface, since heat is 

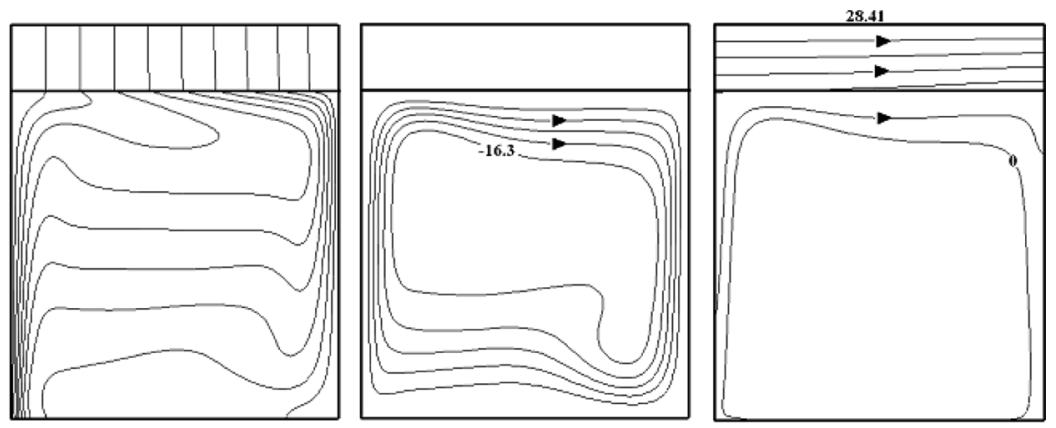

(a)
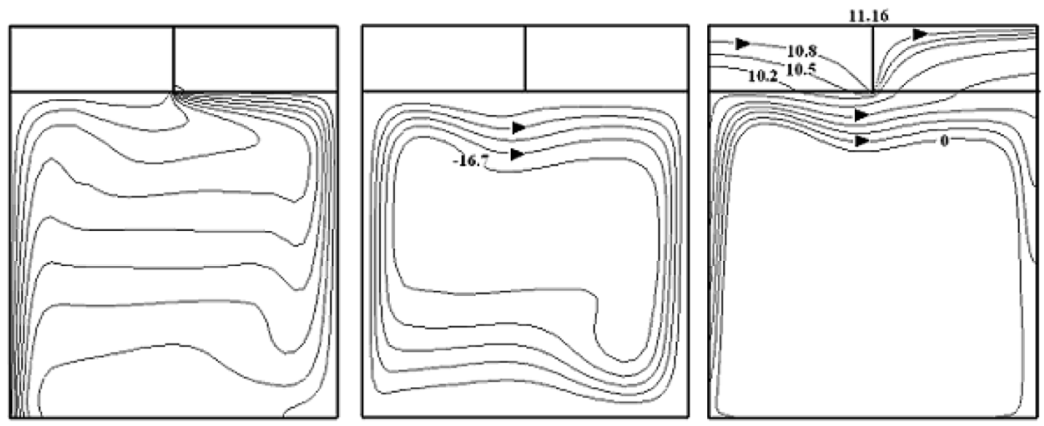

(b)

Figure 6. Isotherms (on the left), streamlines (on the middle), and heatlines (on the right) for $\mathrm{Ra}=10^{6}$ and $K=100$ : (a) without heat barrier, where $\delta \theta=0.1, \delta \Psi=-3.26, \delta H=4.73$; $(b)$ with middle-located heat barrier, where $\delta \theta=0.1, \delta \Psi=-3.34, \delta H=1.86$ (heatlines $10.2,10.5$, and 10.8 were added).

transferred around the heat barrier via fluid. The measure of heat barrier effect on $\overline{\mathrm{Nu}}$ depends on the thermal conductivity ratio. For small values of $K$, the heat barrier does not considerably influence the heat transfer and fluid flow in the fluid region; however, increase of $K$ causes obvious reduction of $\overline{\mathrm{Nu}}$ at the hot and cold vertical walls. For the enclosure with $\mathrm{Ra}=10^{3}$ and $K=1$, the decrease of Nusselt number at $X=1$ due to the heat barrier is $2.5 \%$; however, this value for $K=100$ is $24.3 \%$. The effect of heat barrier on the average Nusselt number decreases with increasing Ra, as shown in Figure $7 b$, since convection heat transfer becomes dominant. The heat barrier reduces $\overline{\mathrm{Nu}}$ at $X=1$ by only $4.7 \%$ for $\mathrm{Ra}=10^{6}$ and $K=100$.

Figures $8 a$ and $8 b$ show the variation of dimensionless conduction heat transfer rate at the right and left vertical boundaries of the ceiling wall for $\mathrm{Ra}=10^{3}$ and $\mathrm{Ra}=10^{6}$, respectively. For the ceiling wall without a heat barrier, the dimensionless heat transfer rates at $X=0$ and $X=1$ approach $Q_{\mathrm{S}}^{*}=0.2$, which is the dimensionless heat transfer rate of the one-dimensional heat conduction case, as the conductivity ratio becomes larger. For the wall with $\mathrm{Ra}=10^{3}$, the heat barrier significantly reduces the heat transfer rate at $X=0$ and $X=1$ ceiling boundaries. The effect of the heat barrier on $Q_{\mathrm{S}}^{*}$ increases with increasing thermal conductivity ratio. For $K=1$ and $R a=10^{3}$, the reduction of the dimensionless heat transfer rate at the $X=1$ boundary is $11.5 \%$, and this value is $91.5 \%$ for $K=100$. The variation 


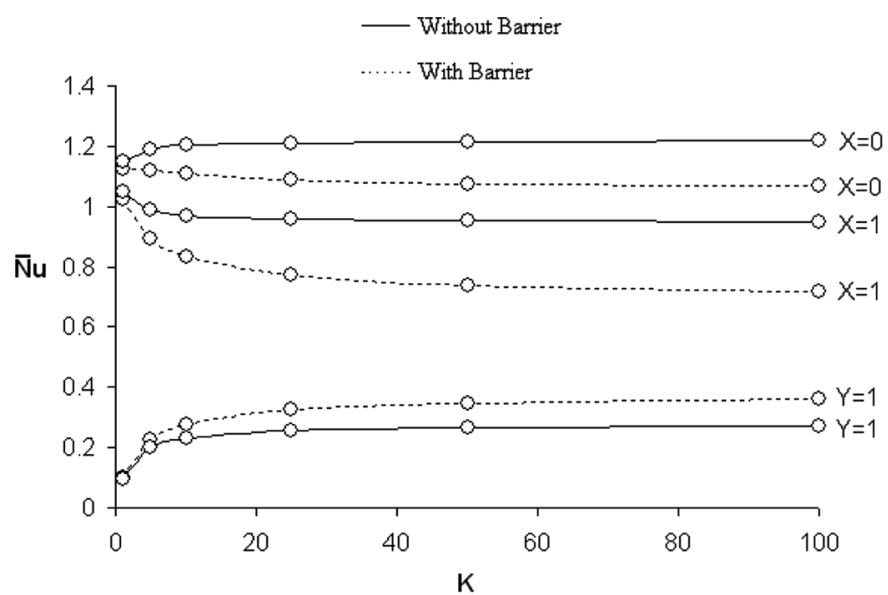

(a)

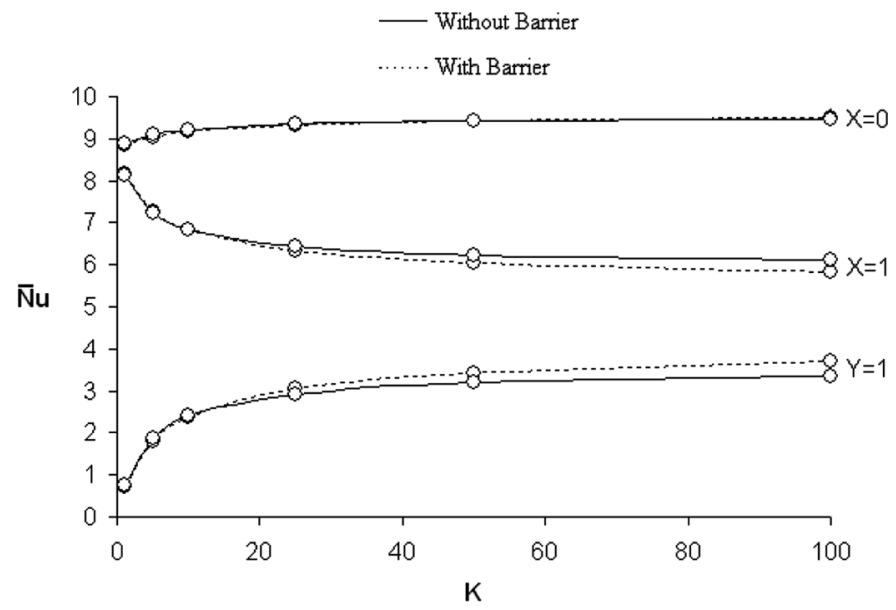

(b)

Figure 7. Variation of average Nusselt number with thermal conductivity ratio at hot and cold vertical walls and ceiling interface for enclosures without heat barrier and with middle-located heat barrier: $(a)$ $\mathrm{Ra}=10^{3} ;(b) \mathrm{Ra}=10^{6}$.

of ceiling wall dimensionless heat transfer rate with thermal conductivity ratio for $\mathrm{Ra}=10^{6}$ is shown in Figure $8 b$. For small values of conductivity ratio (i.e., $\mathrm{K}=1), Q_{\mathrm{S}}^{*}$ is not influenced by the heat barrier, since the strong convection in the fluid region transfers heat from the hot to the cold region of the ceiling. Increase of the thermal conductivity ratio enhances conduction heat transfer through the ceiling. However, the reduction of heat transfer in the ceiling due to the heat barrier cannot be compensated by strong convection. For $\mathrm{Ra}=10^{6}$, the percentage of dimensionless conduction heat transfer reduction due to the heat barrier at $X=1$ for $K=1$ and $K=100$ are $3 \%$ and $76.6 \%$, respectively. Heat transfer through the ceiling wall for $\mathrm{Ra}=10^{3}$ is much affected by the heat barrier when it is compared to $\mathrm{Ra}=10^{6}$. 


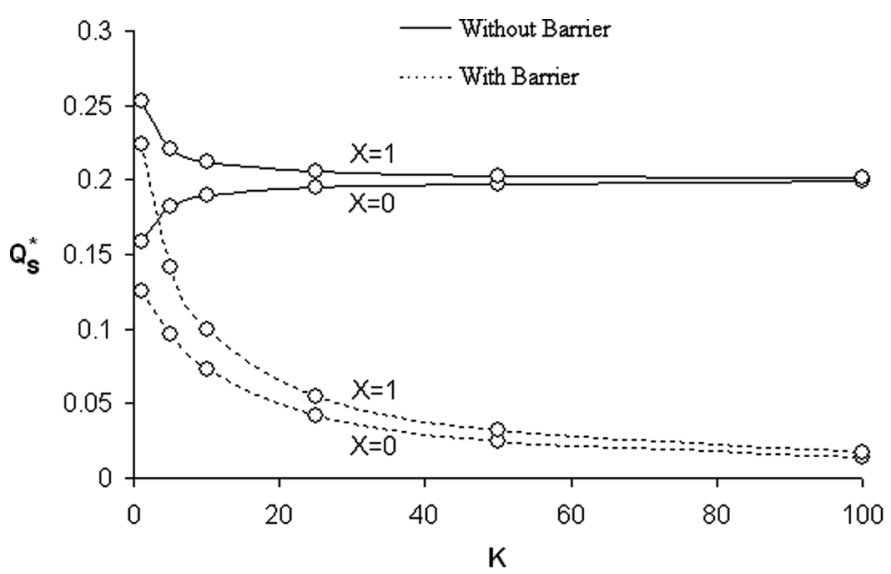

(a)

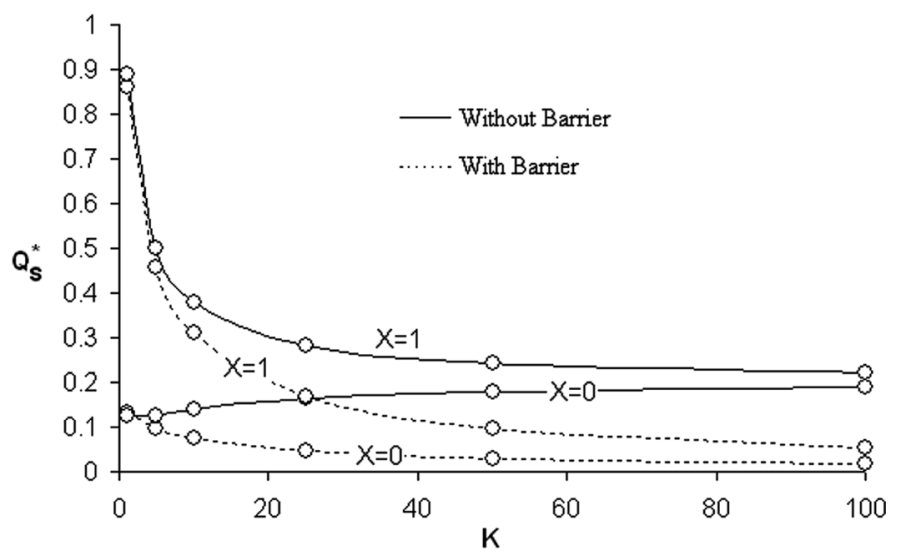

(b)

Figure 8. Variation of $Q_{S}^{*}$ with thermal conductivity ratio at $X=0$ and $X=1$ ceiling walls for enclosures without heat barrier and with middle-located heat barrier: $(a) \mathrm{Ra}=10^{3}$; (b) $\mathrm{Ra}=10^{6}$.

The variation of dimensionless overall heat transfer rate through the enclosure with thermal conductivity ratio for two different Rayleigh numbers, $\mathrm{Ra}=10^{3}$ and $\mathrm{Ra}=10^{6}$, is shown in Figure 9. For the enclosure without a heat barrier, the domination of conduction heat transfer rate in the ceiling wall can be observed, since $Q_{t}^{*}$ increases proportionally with thermal conductivity ratio, due to the proportional increase of one-dimensional conduction heat transfer. For the enclosures with the heat barrier, the overall dimensionless heat transfer rate does not vary for the wide range of thermal conductivity ratio. The reductions of dimensionless overall heat transfer rate due to the heat barrier for $\mathrm{Ra}=10^{3}$ and $\mathrm{Ra}=10^{6}$ when $K=100$ are $755 \%$ and $153 \%$, respectively.

\subsection{Effect of Heat Barrier Location}

For different locations of heat barrier in the ceiling wall with $D=0.20$, numerical results were achieved. Figures $10 a$ and $10 b$ show the isotherms, streamlines, and 


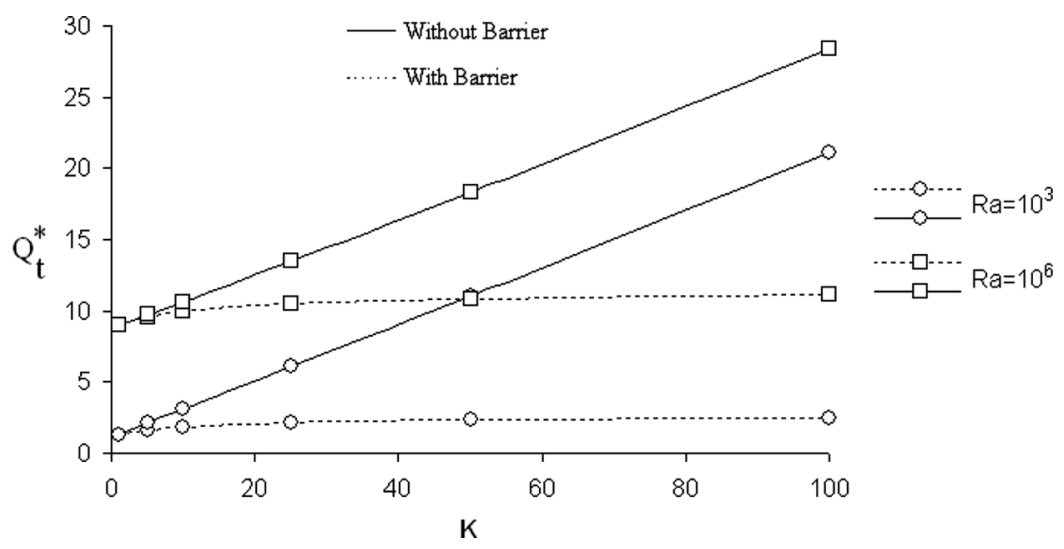

Figure 9. Change of dimensionless overall heat transfer rate with conductivity ratio for enclosures without heat barrier and with middle-located heat barrier: $(a) \mathrm{Ra}=10^{3}$; $(b) \mathrm{Ra}=10^{6}$.

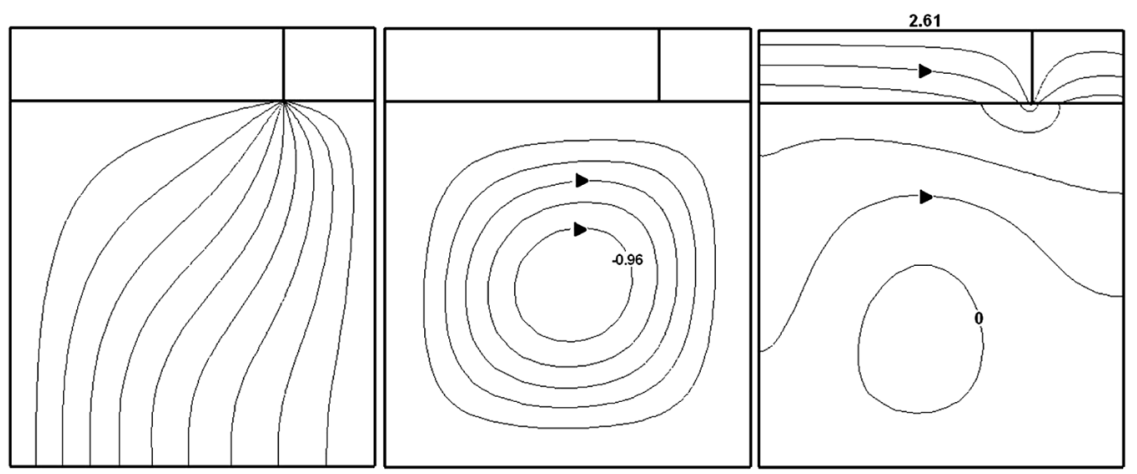

(a)
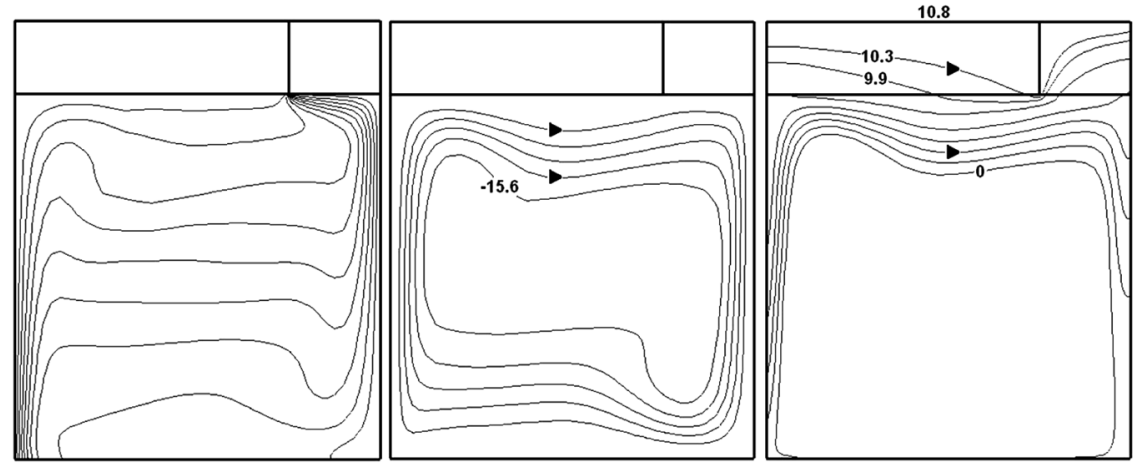

(b)

Figure 10. Isotherms, streamlines, and heatlines for heat barrier location $X_{h}=0.75$ with $K=100$ : $(a)$ $\mathrm{Ra}=10^{3}, \delta \theta=0.1, \delta \Psi=-0.19, \delta H=0.43 ;(b) \mathrm{Ra}=10^{6} ; \delta \theta=0.1, \delta \Psi=-3.1, \delta H=1.8$. 
heatlines for enclosures with $\mathrm{Ra}=10^{3}$ and $\mathrm{Ra}=10^{6}$, respectively. In these figures, the heat barrier is located at $X_{h}=0.75$ and the conductivity ratio is the highest value of the present study $(K=100)$. Similar streamlines, isotherms, and heatlines for the enclosure with a middle-located heat barrier can also be seen for $X_{h}=0.75$. Two separate regions, hot and cold, occur in the ceiling wall, and isotherms are distributed from the edge of the heat barrier. Heat is transferred from the hot to the cold region of the ceiling via fluid. Since the heat barrier is close to the cold vertical boundary, $75 \%$ of the ceiling wall area is at high temperature.

The variations of average Nusselt number of the hot and cold vertical walls and ceiling interface versus heat barrier location are shown in Figure $11 a$ for enclosures with $K=1$ and $K=100$ when $\mathrm{Ra}=10^{3}$. The variation of $\overline{\mathrm{Nu}}$ with heat barrier location for the enclosure with low thermal conductivity ratio (i.e., $K=1$ ) is considerably less than for the enclosure with high thermal conductivity ratio

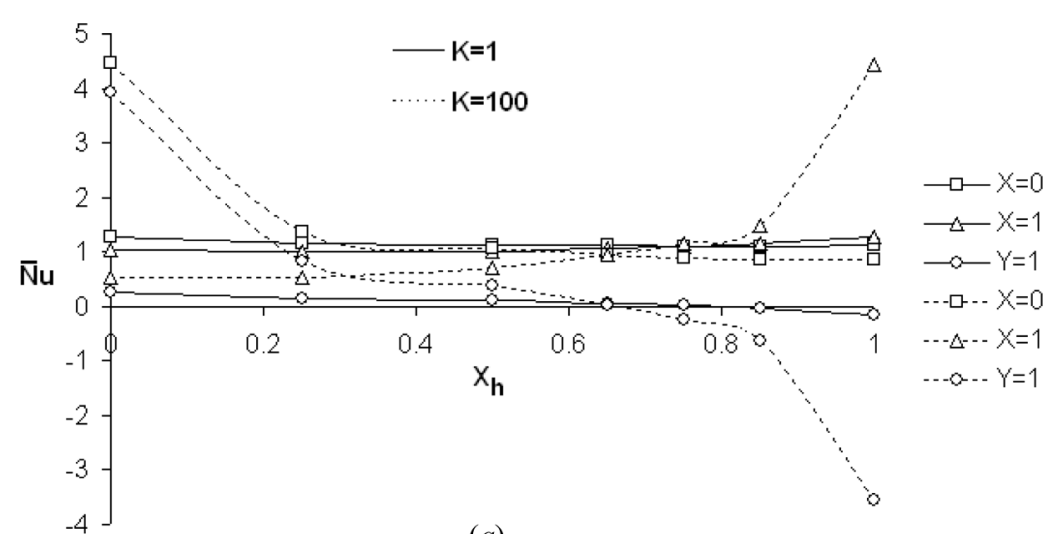

(a)

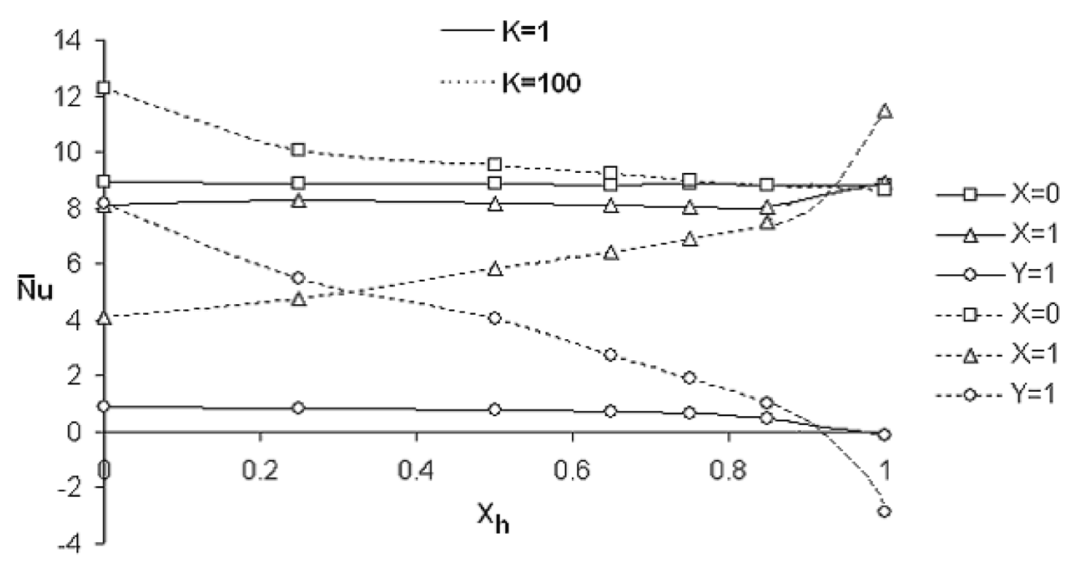

(b)

Figure 11. Change of average Nusselt number of hot and cold walls, and ceiling interface, with heat barrier location for enclosure with $D=0.2$ : $(a) \mathrm{Ra}=10^{3}$; (b) $\mathrm{Ra}=10^{6}$. 
$(K=100)$. Numerical results show that the change of heat barrier location from the hot to the cold wall of the ceiling reduces $\left.\overline{\mathrm{Nu}}\right|_{X=0}$; however, it increases $\left.\overline{\mathrm{Nu}}\right|_{X=1}$. For $K=1$ and $\mathrm{Ra}=10^{3}$, the change of heat barrier location from the left to the right vertical boundary of the ceiling results in a $12 \%$ decrease and a $24 \%$ increase in the average Nusselt numbers of the hot and cold vertical walls, respectively. For $K=100$ and $\mathrm{Ra}=10^{3}$, movement of the heat barrier in the ceiling from the left to the right vertical wall causes a $99 \%$ decrease and a $748 \%$ increase in the average Nusselt numbers of the boundaries at $X=0$ and $X=1$, respectively. As was mentioned before, two separate cold and hot regions form in the right and left sides of the heat barrier of the ceiling wall as thermal conductivity ratio increases. The change of heat barrier location from left to right increases the hot region area and, consequently, the cold region area is reduced. This causes the decrease of the $\left.\overline{\mathrm{Nu}}\right|_{X=0}$ and the rise of the $\left.\overline{\mathrm{Nu}}\right|_{X=1}$ curves. The value of average Nusselt number at the interface, $\left.\overline{\mathrm{Nu}}\right|_{Y=1}$, is positive and maximum at $X_{h}=0$. The change of heat barrier location from left to right results in a reduction in the average Nusselt number of the interface. It becomes zero for a heat barrier location around $X_{h}=0.80$ and $X_{h}=0.65$ for the ceiling walls with $K=1$ and $K=100$, respectively, and then $\left.\overline{\mathrm{Nu}}\right|_{Y=1}$ takes negative values. The negative sign of average Nusselt number shows that the rate of heat transfer from solid to fluid is greater than that from fluid to solid at the interface. The variation of average Nusselt number with heat barrier location for the cavity with $\mathrm{Ra}=10^{6}$ is shown in Figure $11 \mathrm{~b}$. Similar to the enclosure with $\mathrm{Ra}=10^{3}$ (Figure 11a), the change of heat barrier location reduces the value of $\left.\overline{\mathrm{Nu}}\right|_{X=0}$ while it increases $\left.\overline{\mathrm{Nu}}\right|_{X=1}$. For $K=1$, the shift of heat barrier from the left to the right boundary of the ceiling results in a $2 \%$ decrease and an $11 \%$ increase of the average Nusselt numbers at $X=0$ and $X=1$. For $K=100$, the average Nusselt number at $X=0$ and $X=1$ vertical walls decreases $30 \%$ and increases $178 \%$, respectively, with the change of heat barrier location. The value of $\left.\overline{\mathrm{Nu}}\right|_{Y=1}$ is maximum for $X_{h}=0$, and it decreases when the heat barrier moves to $X_{h}=1$. The interface average Nusselt number becomes zero around $X_{h}=0.96$ for $K=1$ and $X_{h}=0.90$ for $K=100$ when $\mathrm{Ra}=10^{6}$.

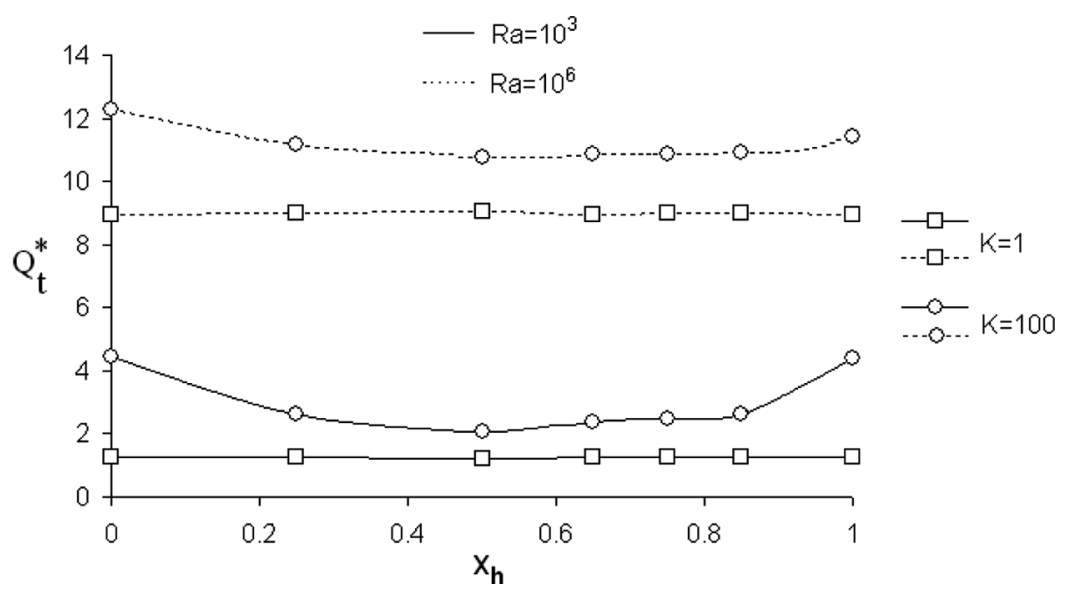

Figure 12. Change of dimensionless overall heat transfer rate $Q_{t}^{*}$ with heat barrier location for enclosure with $D=0.2$ : (a) $\mathrm{Ra}=10^{3} ;(b) \mathrm{Ra}=10^{6}$. 
The variation of the overall dimensionless heat transfer rate, $Q_{t}^{*}$, with heat barrier location for an enclosure with $D=0.20$ is illustrated in Figure 12 for $K=1$ and $K=100$ and for two different Rayleigh numbers, $\mathrm{Ra}=10^{3}$ and $\mathrm{Ra}=10^{6}$. The change of heat barrier location does not considerably affect dimensionless overall heat transfer rate through the enclosure for $K=1$, though an effect of heat barrier location is seen for $K=100$ and $\mathrm{Ra}=10^{3}$. Particularly for the enclosure with $\mathrm{Ra}=10^{3}$, a minimum point for dimensionless overall heat transfer rate is observed. Movement of the heat barrier from $X_{h}=0$ to $X_{h}=0.5$ results in a decrease of $53 \%$ in the dimensionless overall heat transfer rate and then an increase behind $X_{h}=0.5$. However, for $K=100$ and $\mathrm{Ra}=10^{6}, Q_{t}^{*}$ decreases, it is almost constant behind $X_{h}=0.5$, and then it rises slightly in the region close to the cold wall. Movement

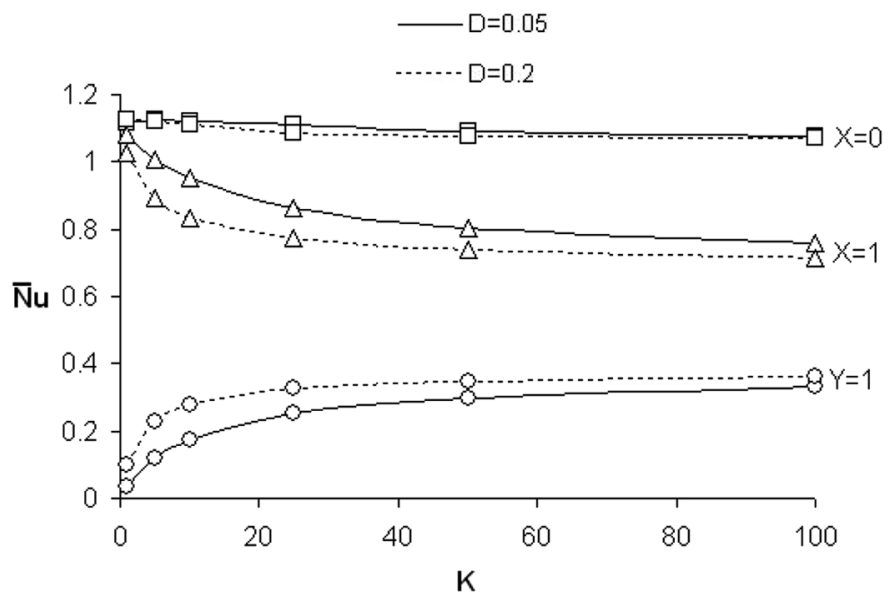

(a)

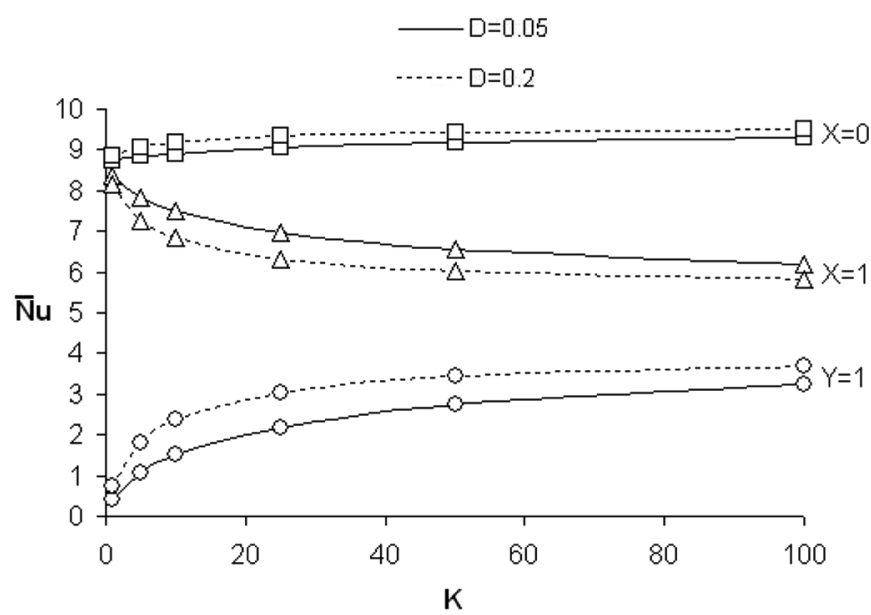

(b)

Figure 13. Variation of average Nusselt number (at $X=0, X=1$ and $Y=1$ ) with thermal conductivity ratio for the enclosures with $X_{h}=0.5$ and dimensionless ceiling wall thicknesses $D=0.05$ and $D=0.2$ : (a) $\mathrm{Ra}=10^{3} ;\left(\right.$ b) $\mathrm{Ra}=10^{6}$. 
of the heat barrier from $X_{h}=0$ to $X_{h}=0.5$ results in a decrease of $11 \%$ in the overall dimensionless heat transfer rate, which is smaller than the results of the enclosure with $\mathrm{Ra}=10^{3}$ because of strong convection heat transfer in the fluid region.

\subsection{Effect of Ceiling Wall Thickness}

Two different ceiling wall thicknesses are examined to see the effects of this parameter on the dimensionless heat transfer through the enclosure with $X_{h}=0.5$. Figure 13 shows the variation of average Nusselt number at the hot and cold walls, and the interface, with thermal conductivity ratio for two different ceiling wall thicknesses $(D=0.05$ and $D=0.2)$ and for two Rayleigh numbers, $10^{3}$ and $10^{6}$. For $\mathrm{Ra}=10^{3}$, the increase of ceiling thickness slightly increases $\overline{\mathrm{Nu}}$ at the interface, and it decreases $\overline{\mathrm{Nu}}$ of the cold vertical wall; however, the wall thickness does not have significant influence on the average Nusselt number of the hot wall. For $\mathrm{Ra}=10^{6}$, the increase of ceiling wall thickness has the same effect as in the $\mathrm{Ra}=10^{3}$ case; however, it slightly increases $\left.\overline{\mathrm{Nu}}\right|_{X=0}$. The change of wall thickness from 0.05 to 0.2 results in $2 \%$ and $14 \%$ increase in $\left.\overline{\mathrm{Nu}}\right|_{X=0}$ and $\left.\overline{\mathrm{Nu}}\right|_{Y=1}$, respectively, and $6 \%$ decrease in $\left.\overline{\mathrm{Nu}}\right|_{X=1}$ for $\mathrm{Ra}=10^{6}$ and $K=100$.

The variation of dimensionless overall heat transfer rate through the enclosure with conductivity ratio for two Rayleigh number values, $\mathrm{Ra}=10^{3}$ and $\mathrm{Ra}=10^{6}$, and for two different middle-located heat barrier ceiling wall thicknesses ( $D=0.05$ and $D=0.20$ ), is shown in Figure 14 . For low conductivity ratio (i.e., $K=1$ ), the increase of wall thickness has a smaller effect on the dimensionless overall heat transfer rate compared with the high conductivity ratio (i.e., $K=100$ ). The heat barrier considerably prevents heat transfer in the ceiling wall, and $Q_{t}^{*}$ is not highly affected with the increase of ceiling thickness. For $K=1$, the increase of ceiling thickness causes $0.9 \%$ and $2.1 \%$ increase in $Q_{t}^{*}$ for $\mathrm{Ra}=10^{3}$ and $\mathrm{Ra}=10^{6}$,

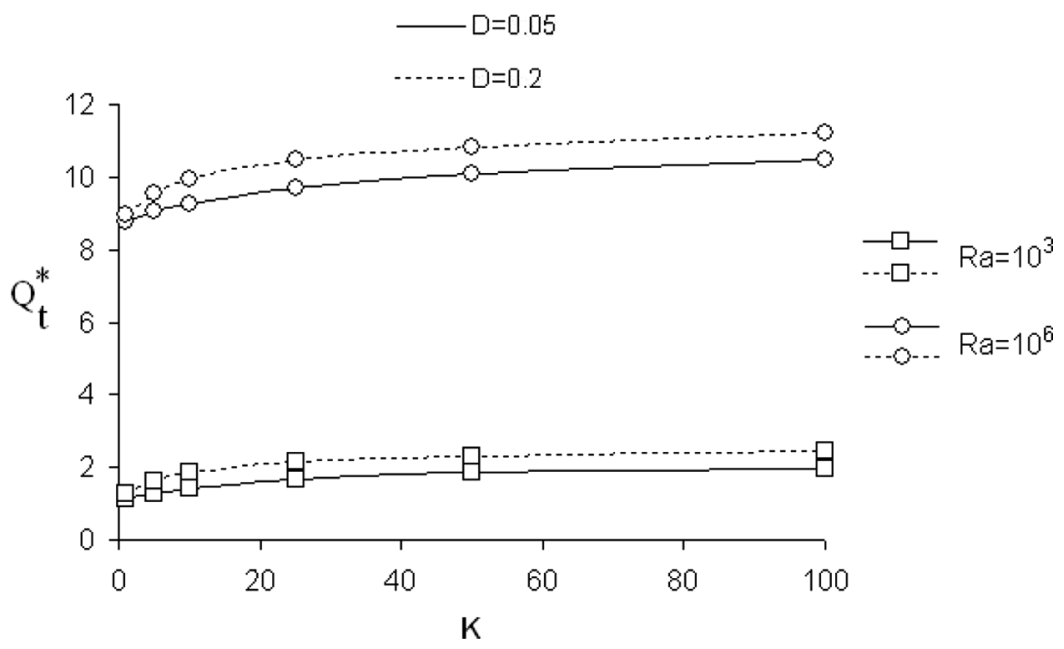

Figure 14. Variation of dimensionless overall heat transfer rate with thermal conductivity ratio for $\mathrm{Ra}=10^{3}$ and $\mathrm{Ra}=10^{6}$, two dimensionless wall thicknesses $D=0.05$ and 0.2 , and $X_{h}=0.5$. 
respectively. For $K=100$, the increase of ceiling thickness from 0.05 to 0.2 causes an increase of total dimensionless heat transfer rate by $25 \%$ and $6.5 \%$ for $\mathrm{Ra}=10^{3}$ and $\mathrm{Ra}=10^{6}$, respectively.

\subsection{Effect of Rayleigh Number}

The variations of average Nusselt number and dimensionless overall heat transfer rate with Rayleigh number are shown in Figures $15 a$ and $15 b$ for enclosures with and without heat barrier when $K=100$. The heat barrier is located at the middle of the ceiling, and $D=0.20$. The average Nusselt number at the hot walls

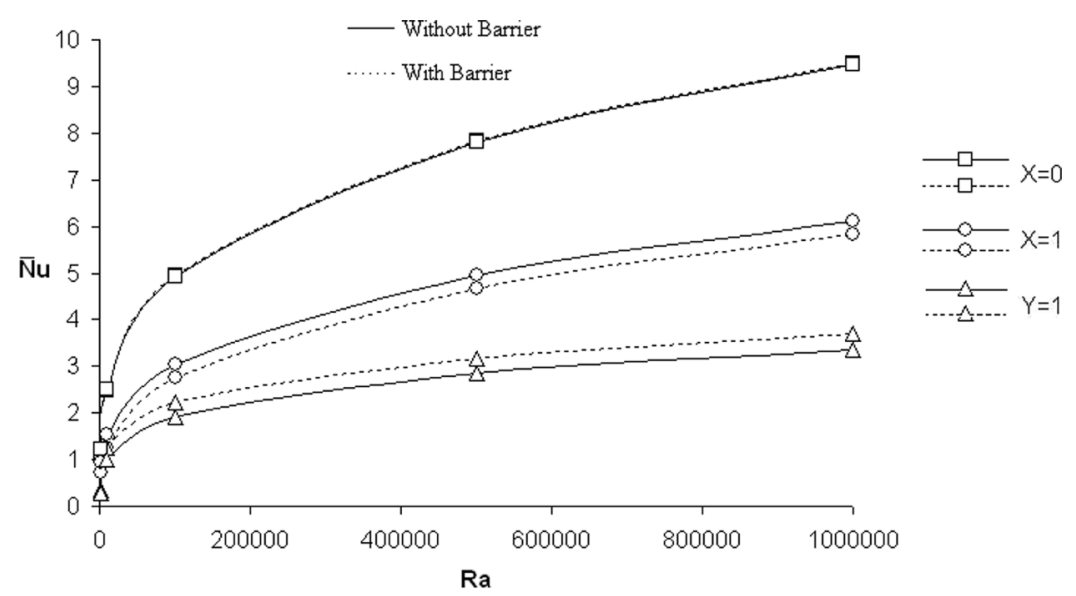

(a)

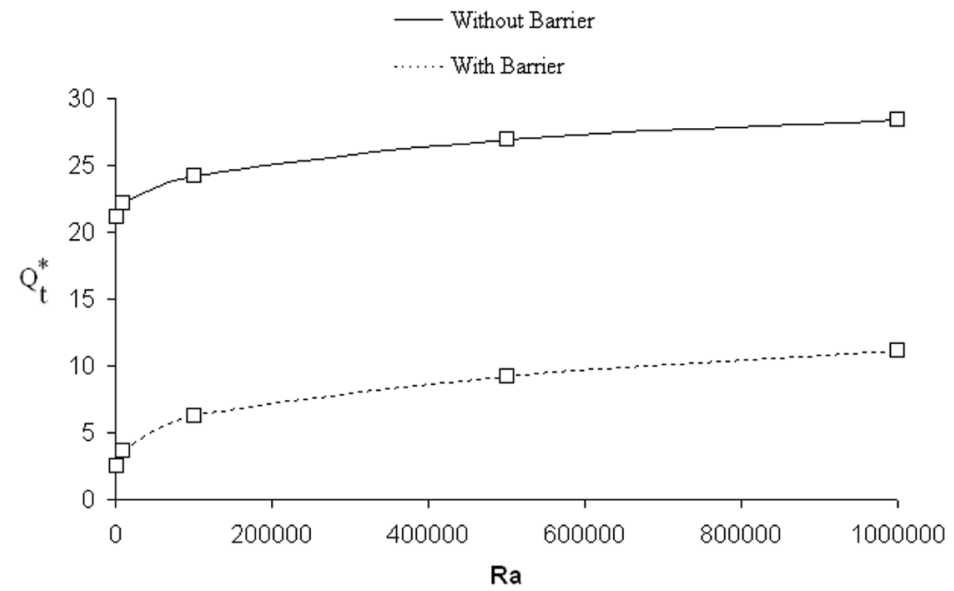

(b)

Figure 15. Change of average Nusselt number (at $X=0, X=1$ and $Y=1$ ) and dimensionless overall heat transfer rate with Rayleigh number for enclosures with heat barrier at $X_{h}=0.5$ and without heat barrier where $K=100$ : $(a)$ average Nusselt number; $(b)$ dimensionless overall heat transfer rate. 
of both enclosures is almost the same for all values of Rayleigh number. The temperature of air which flows horizontally on the upper region of fluid region is influenced by the heat barrier, and consequently $\left.\overline{\mathrm{Nu}}\right|_{X=1}$ decreases slightly. Figure $15 b$ shows the variation of dimensionless overall heat transfer rate with Rayleigh number for the same enclosures as in Figure 15a. As is seen, the increase of Rayleigh number causes an increase of overall dimensionless heat transfer rate for both enclosures with and without a heat barrier. The heat barrier considerably reduces dimensionless overall heat transfer rate through the enclosure, since heat is largely transferred between the vertical walls of the enclosure by conduction in the ceiling.

\section{CONCLUSION}

The effects of a heat barrier and its location in the ceiling wall of an enclosure have been investigated for Rayleigh number changing from $10^{3}$ to $10^{6}$ and in the thermal conductivity ratio range of 1 to 100 . Heatlines are employed to observe the mechanism of heat transfer between the ceiling wall and the fluid. It is observed that heatlines are efficient tools, since they indicate the path of heat from solid to fluid and vice versa. The results obtained are useful for manufacturers who work on the design of thermal breakers to reduce heat leakage. By considering the results obtained the following conclusions are drawn:

1. For low thermal conductivity ratio, mean Nusselt number is not greatly affected by a heat barrier. The heat barrier changes the direction of heat flow in the ceiling and, as a result, heat has to be transferred from the hot to the cold side of the ceiling via fluid. For higher thermal conductivity ratio, the heat barrier causes the formation of two separate cold and hot regions in the ceiling. The dimensionless overall heat transfer through the enclosure is considerably influenced by the heat barrier.

2. The average Nusselt numbers of the hot and cold walls are reduced by the heat barrier. The decreasing effect is greater for high thermal conductivity ratio and low Rayleigh number values.

3. A heat barrier location was observed where the average Nusselt numbers of the hot and cold vertical walls are equal.

4. The heat barrier causes significant changes in the dimensionless heat transfer rate at the vertical boundaries of the ceiling. It considerably reduces the dimensionless heat transfer rate of both boundaries. This effect decreases with increasing Rayleigh number.

5. Changing the heat barrier location from the hot to the cold boundary decreases the average Nusselt number of the hot boundary while it increases the coldboundary average Nusselt number.

6. The effect of heat barrier location on dimensionless overall heat transfer rate is greater for enclosures with low Rayleigh number. There is a heat barrier location where dimensionless overall heat transfer rate is minimum. For the enclosure with $\mathrm{Ra}=10^{3}$ and $K=100$, movement of the heat barrier from $X_{h}=0$ to $X_{h}=0.5$ results in a decrease of $53 \%$ in dimensionless overall heat transfer rate.

7. For the enclosure with a middle-located heat barrier and high conductivity ratio, the overall dimensionless heat transfer rate is influenced by the change of wall 
thickness. For instance, the dimensionless thickness change of $D=0.05$ to $D=0.2$ results in a $25 \%$ increase in $Q_{t}^{*}$ for $\mathrm{Ra}=10^{3}$ and $K=100$.

\section{REFERENCES}

1. D. M. Kim and R. Viskanta, Effect of Wall Heat Conduction on Natural Convection Heat Transfer in a Square Enclosure, ASME J. Heat Transfer, vol. 107, pp. 139-146, 1985.

2. D. A. Kaminski and C. Prakash, Conjugate Natural Convection in a Square Enclosure: Effect of Conduction in One of the Vertical Walls, Int. J. Heat Mass Transfer, vol. 12, pp. 1979-1988, 1986.

3. D. Misra and A. Sarkar, Finite Element Analysis of Conjugate Natural Convection in a Square Enclosure with a Conducting Vertical Wall, Comput. Meth. Appl. Mech. Eng., vol. 141, pp. 205-219, 1997.

4. R. B. Yedder and E. Bilgen, Laminar Natural Convection in Inclined Enclosures Bounded by a Solid Wall, Heat and Mass Transfer, vol. 32, pp. 455-462, 1997.

5. A. Liaqat and A. C. Baytaş, Conjugate Natural Convection in a Square Cavity Enclosure Containing Volumetric Sources, Int. J. Heat Mass Transfer, vol. 44, pp. 3273-3280, 2001.

6. Y. Varol, H. F. Oztop, and A. Koca, Entropy Generation due to Conjugate Natural Convection in Enclosures Bounded by Vertical Solid Walls with Different Thicknesses, Int. Commun. Heat Mass Transfer, doi:10.1016/j.icheatmasstransfer.2008.01.010, 2008.

7. D. M. Kim and R. Viskanta, Study of Effects of Wall Conductance on Natural Convection in Differently Oriented Square Cavities, J. Fluid Mech., vol. 144, pp. 153-176, 1984.

8. S. Acharya and C. H. Tsang, Influence of Wall Conduction on Natural Convection in an Inclined Square Enclosure, Warme and Stoffübertragunug, vol. 21, pp. 19-30, 1987.

9. M. A. I. El-Shaarawi and A. A. A. Negm, Conjugate Natural Convection Heat Transfer in an Open-Ended Vertical Concentric Annulus, Numer. Heat Transfer A, vol. 36, pp. 639-655, 1999.

10. B. Morrone, Natural Convection between Parallel Plates with Conjugate Conductive Effects, Numer. Heat Transfer A, vol. 40, pp. 873-886, 2001.

11. D. M. Kim and R. Viskanta, Heat Transfer by Conduction, Natural Convection and Radiation across Rectangular Cellular Structure, Int. J. Heat Fluid Flow, vol. 5, pp. 205-212, 1984.

12. C. G. Rao, Buoyancy-Aided Mixed Convection with Conduction and Surface Radiation from a Vertical Electronic Board with a Traversable Discrete Heat Source, Numer. Heat Transfer A, vol. 45, pp. 935-956, 2004.

13. B. Larbi, Statistical Modeling of Heat Transfer for Thermal Bridges of Buildings, Energy and Buildings, vol. 37, pp. 945-951, 2005.

14. A. E. Ben Nakhi, Minimizing Thermal Bridging through Window Systems in Buildings of Hot Regions, Appl. Thermal Eng., vol. 22, pp. 989-998, 2002.

15. S. Y. Song, J. H. Jo, M. S. Yeo, Y. D. Kim, and K. D. Song, Evaluation of Inside Surface Condensation in Double Glazing Window System with Insulation Spacer: A Case Study of Residential Complex, Building and Environment, vol. 42, pp. 940-950, 2007.

16. M. Tosun, M. Mobedi, and B. Ozerdem, Heat Transfer through Casing of an Air Handling Unit, 37th HVAC\&R Congress, Belgrade, Serbia, 2006.

17. T. Höglund and H. Burstrand, Slotted Steel Studs to Reduce Thermal Bridges in Insulated Walls, Thin Walled Structures, vol. 32, pp. 81-109, 1998.

18. S. Kimura and A. Bejan, The Heatline Visualization of Convective Heat Transfer, ASME J. Heat Transfer, vol. 105, pp. 916-919, 1983. 
19. V. A. F. Costa, Bejan's Heatlines and Masslines for Convection Visualization and Analysis, Appl. Mech. Rev., vol. 59, pp. 126-145, 2006.

20. M. Mobedi, Conjugate Natural Convection in a Square Cavity with Finite Thickness Horizontal Walls, Int. Commun. Heat Mass Transfer, vol. 35, pp. 503-513, 2008.

21. M. Mobedi and H. Yuncu, A Three Dimensional Numerical Study on Natural Convection Heat Transfer from Short Horizontal Rectangular Fin Array, Heat and Mass Transfer, vol. 39, pp. 267-275, 2003.

22. K. L. Wong and A. J. Baker, A 3D Incompressible Navier-Stokes Velocity Vorticity Weak Form of Finite Element Algorithm, Int. J. Numer. Meth. Fluids, vol. 38, pp. 99-123, 2002.

23. G. de Vahl Davis, Natural Convection of Air in a Square Cavity; A Bench Mark Numerical Solution, Int. J. Numer. Meth. Fluids, vol. 3, pp. 249-264, 1983. 